Semina $\square \quad \mathrm{Nr} 14$

Scientiarum 2015

s. $82-91$

DOI: http://dx.doi.org/10.15633/ss. 1080

Adrianna Kępińska

\title{
Is normal science good science? ${ }^{1}$
}

\section{Introduction}

Thomas Kuhn's idea of normal science aroused controversy and discussion on nature of the scientific enterprise. ${ }^{2}$ Similarly, "good science" could be understood in multiple ways, i.e. having "psychological" qualities, the concept forwarded by Kuhn; or "intellectual" qualities, the concept represented by Karl Popper, among others. With such an intricate web of concepts, it could be argued that there are a few ways of answering the question of whether normal science is good science. One way is to examine whether Kuhn's psychological features of science were advantageous. The criticism of Kuhn's account would imply that good science has other distinctive features and that maybe normal science is good in an intellectual, but not psychological sense. Consequently, the Popperian account is analyzed, together with some criticisms on that account, and a more balanced "middle ground" vision of normal science by Feyerabend ${ }^{3}$

1 The paper was originally submitted as an assignment for the course Introduction to the History and Philosophy of Science under the supervision of Miss Rachel Dunn at Durham University, UK. It was also awarded with the title of Highly Commended at the 2014 competition for undergraduate students, The Undergraduate Awards.

2 Compare e.g. with essays in Criticism and the Growth of Knowledge. Proceedings of the International Colloquium in the Philosophy of Science, ed. I. Lakatos, A. Musgrave, London 1965, Cambridge 1970.

3 Compare with P. Feyerabend, Consolations for the Specialist, [in:] Criticism and the Growth of Knowledge, op. cit., p. 197-230. 
is presented. This paper aims to show that a clear-cut answer of whether normal science is good science seems difficult.

\section{Exegesis}

Normal science was a concept popularized by Kuhn in his 1962 book The Structure of Scientific Revolutions. ${ }^{4}$ Normal science took place after an establishment of the paradigm, the framework most successful in solving the current most important scientific problems. ${ }^{5}$ Its goal was the "articulation of [...] phenomena and theories that the paradigm already supplies" ${ }^{\prime 6}$ and "puzzle-solving". ${ }^{7}$ Instead of producing major novelties, it aimed at solving problems within the paradigm, i.e. problems whose outcome had been assured to be found (indicated by the existence of the general paradigm), similarly like in a puzzle. ${ }^{8}$

"Good science" is a broad expression. Philosophers involved in discussion on normal science have proposed different features of it. Kuhn suggested that he had dealt more with the problem of psychological aspects, the way that scientists interact to reach conclusions, scientists' drives and values that lead them to work within the normal research conditions. ${ }^{9}$ Hence good science could be psychologically rewarding motivating, interesting, and coherent with the scientist's point of view, and convincing for the community to which the scientist belongs. According to a Popperian, intellectual point of view, ${ }^{10}$ good science should stand several rigorous attempts

4 See J. Watkins, Against 'Normal Science', [in:] Criticism and the Growth of Knowledge, op. cit., p. 25.

5 See T. S. Kuhn, The Structure of Scientific Revolutions. Fourth Edition, Chicago-London 2012, p. 24.

6 T. S. Kuhn, The Structure of Scientific Revolutions, op. cit., p. 24.

7 T. S. Kuhn, The Structure of Scientific Revolutions, op. cit., p. 35.

8 Compare with T. S. Kuhn, The Structure of Scientific Revolutions, op. cit., p. 36.

9 Compare with T. S. Kuhn, Logic of Discovery or Psychology of Research?, [in:] Criticism and the Growth of Knowledge, op. cit., p. 21-22.

10 See K. Popper, Conjectures and Refutations. The Growth of Scientific Knowledge, London-New York 2004, p. 291. 
of falsification and refutation by observation. ${ }^{11}$ Good science would be objective rather than epistemic. ${ }^{12}$

\section{Good "Psychological" Normal Science: Analysis}

Kuhn's account could be perceived as an attempt at explaining engagement in normal science on the grounds of motivation and reward. The aim was not a theoretical novelty. Research outcomes were clearly anticipated because they were provided by the paradigm. Instead, another challenge appeared: solutions of unresolved problems within a paradigm with the use of sophisticated ${ }^{13}$ methods. The need for sophistication was necessary, as it provided scientists with challenges of genuine interest. ${ }^{14}$ In later discussions, Kuhn suggests that "it is the individual rather than current theory which is tested". ${ }^{15}$ It can be understood as a further interpretation of the psychological aspects of science; not only does a scientist get attracted to a problem because it is generally challenging as unresolved (thus being the goal shared by many researchers), but there also appears an element of ambition and even rivalry among scholars because of the introduction of a qualitative element; it leads them to compete as to whose solution is more sophisticated.

11 Compare with P. Godfrey-Smith, Theory and Reality: An Introduction to the Philosophy of Science, Chicago-London 2003, p. 58.

12 Compare with K. Popper, Conjectures and Refutations, op. cit., p. 302-309.

13 "Sophisticated" is understood in this essay as a very widely comprehended "refined," superior to prior attempts, because it appears close to Kuhn's thought on problem-solving as "problems that can serve to test ingenuity or skill in solution" (T. S. Kuhn, The Structure of Scientific Revolutions, op. cit., p. 37). It is worth to clarify it, because "sophisticated" can also relate to "complex" and, as it has been pointed out by e.g. A. Baker, there actually is "a widespread philosophical presumption that simplicity is a theoretical virtue" and a controversial discussion on the extent to which it is correct (compare with par. 1 in A. Baker, Simplicity, [in:] http:// plato.stanford.edu/archives/sum2011/entries/simplicity/ (1.02.2013)). This discussion, however, is not a concern central to the definition of good science proposed in this essay.

14 See T. S. Kuhn, The Structure of Scientific Revolutions, op. cit., p. 36.

15 T. S. Kuhn, Logic of Discovery or Psychology of Research?, op. cit., p. 5. 
Kuhn's "psychological” scientific enterprise may seem intuitively appealing by showing a more "humane" side of research. Still, it was argued that 'Kuhn's use of [...] the 'puzzle' was indicative of a wish to show that the problems so described are not [...] very deep". ${ }^{16}$ However, it is probable that Kuhn implemented the expression to indicate the mechanism underneath these problems, to emphasize their having a solution, like jigsaws do, not to assess normal science qualitatively. Moreover, Hacking has pointed out that (initially shocked) scientists admitted that Kuhn's description indeed resembles their daily work. ${ }^{17}$

Kuhn listed attitudes as reasons behind engaging in normal science: "the desire to be useful, the excitement of exploring new territory, the hope of finding order, and the drive to test established knowledge". ${ }^{18}$ Such a personal approach seems subjective, inconsistent with one of suggested features of good science: objectivity. Conversely, it could be argued that subjectivity may lead to a mutual advantage without colliding with objectivity in the wider perspective. In the aforementioned list of motivations, there is "a desire to be useful", probably useful to the community assessing the paradigm implementation. A strongly motivated scientist contributed to methodological development (organizing knowledge, improved testing) that could be "the shared good". It indirectly helped multiple members of the community, even if the drive to complete the "puzzle" was primarily to satisfy an individual.

Assuming that the research results have to be acknowledged by the scientific community suggests that, at least to some extent (perhaps people guided by the same paradigm), they are not entirely subjective. The results are exposed to criticism to identify problems and hence bring them closer to objectivity (or at least to lesser subjectivity). That would imply that normal science is good.

${ }_{16}$ K. Popper, Normal Science and Its Dangers, [in:] Criticism and the Growth of Knowledge, op. cit., p. 53.

17 Compare with I. Hacking, Introductory Essay, [in:] T. S. Kuhn, The Structure of Scientific Revolutions, op. cit., p. XVI.

18 T. S. Kuhn, The Structure of Scientific Revolutions, op. cit., p. 38. 
It rewards both scientists and their communities in some kind of bidirectional cooperation: the scientist has to be motivated to deliver useful results to the community but the community boosts their motivation and satisfaction by acknowledging their findings, which motivates scientists to continue their work and develop the paradigm scope which, in general, is the major community goal.

\section{Problems with the "Psychologism" of Normal Science}

Watkins focused on connections between normal science and the paradigm change. ${ }^{19}$ Yet his paradigm-centered critique illustrates the controversy surrounding the psychological aspects of normal science. The Instant-Paradigm Thesis was Watkins' name for Kuhn's idea from Structure... that inventing theories that are eventually crucial for a paradigm shift takes place at once, sometimes performed by a single person. ${ }^{20}$ Watkins considered an assumption of the religious-like ${ }^{21}$ dedication to the paradigm. He noticed that the new paradigm must have enough power to convince a scientist to completely change his or her thinking. It is improbable, Watkins argued, for an immediate result of work of a single scientist to be that strong. ${ }^{22}$

In light of Watkins' insight, it may seem that normal science is psychologically complicated because Kuhn did not specify the extent to which scientists devote themselves to new theories underlying their normal scientific enterprise. In order to forward his paradigm criticism, it was Watkins who explicitly interpreted Kuhn's rather vague remarks on, for example, how scientific training resembles orthodox theology ${ }^{23}$ the emphasis on individual motivation behind research. It would suggest that the main drive is actually "conform-

19 See J. Watkins, Against 'Normal Science', op. cit., p. 27.

20 J. Watkins, Against 'Normal Science', op. cit., p. 35.

21 Compare with T. S. Kuhn, The Structure of Scientific Revolutions, op. cit., p. 165.

22 See J. Watkins, Against 'Normal Science', op. cit., p. 35.

23 T. S. Kuhn, The Structure of Scientific Revolutions, op. cit., p. 165. 
ing" to the community and the paradigm rather than individual acknowledgement. If Kuhn was right, then normal science could be considered as a high motivational factor for scientists, with its positive aspects of being rewarding and organizing scientific work to be accepted, hence "a good science".

On the other hand, Watkins' critique suggests a likelihood of normal science being disappointing, at least in crisis. Facing the research shortcomings and the possibility of their solutions being at least prior to the establishment of a new paradigm, scientists may incorrectly feel disappointment proportional to their earlier belief. Consequently, accepting Watkins' view would yield for reformulation of the definition of good science by excluding psychological factors or maybe even by stating that normal science is not really good.

\section{The "Intellectual" Perspective and Further Criticisms}

In reply to Kuhn, Feyerabend asked "do scientists stick to their paradigms to the bitter end until disgust, frustration and boredom makes it quite impossible for them to go on?"24 This would support Watkins' view. In a sense, however, Feyerabend went even further: "This is quite imaginable that scientists abandon a paradigm out of frustration and not because they have arguments against it". ${ }^{25}$ That critique would suggest that it is impossible for psychological reward and objectivity to be both features of normal science as there are cases in which the psychological (emotional) judgment is the main factor of scientific change.

That interpretation is in contrast to the "intellectual" perspective. Popper considered the lack of objectivity to be a problem, with the scientist being "a prisoner [...] in the framework of [...] theories; [...] expectations; [...] past experiences; [...] language" ${ }^{26}$ His solution was

24 P. Feyerabend, Consolations for the Specialist, op. cit., p. 205.

25 P. Feyerabend, Consolations for the Specialist, op. cit., p. 203.

26 K. Popper, Normal Science and Its Dangers, op. cit., p. 56. 
the ongoing refutation of conjectures: "again in the framework, but [...] a better and roomier one; and we can at any moment break it out again". ${ }^{27} \mathrm{He}$ further criticized normal science for an over-dedication to community that limits the critical attitude towards the outcomes of research. Popper called normal science "indoctrination", ${ }^{28}$ which evokes strong pejorative connotations. However, linking it with an earlier suggestion of a scientist relying on the community's judgment gives the possibility of forwarding a new critical point; perhaps a scientist's attitude to his or her work in the process of completing said work is determined by the expectations of the community and tradition, not really how people "feel" but how they were "taught to feel". That would expose a serious circularity of normal science: people engage in it because it is powerful; it is powerful because people are presented with that view at the beginning (and probably throughout) their academic career.

Finally, Popper criticized assuming the lack of novelty within the normal science. He pointed out that there is some novelty in the sciences that Kuhn would consider primarily descriptive, hence "normal"; such as in the case of a biologist who has to carry experiments on plants at every step of creating his descriptive classification. ${ }^{29}$ In short, "Kuhn, and perhaps others, was surely too focused on [...] theoretical physics". ${ }^{30}$ If so, then normal science could be considered "not good" not only on the grounds of outcomes, but, more generally, of its supposed mechanism.

Feyerabend discusses the pattern of revolution. According to him, the revolution did not really exist in a form "in which professional stupidity is periodically replaced by philosophical outbursts only to return again at a "higher level"', ${ }^{31}$ meaning that the criticism probably enters the normal scientific process earlier, not only in crisis (similarly, probably, to Popper in this aspect). Still, his

27 K. Popper, Normal Science and Its Dangers, op. cit., p. 56.

28 K. Popper, Normal Science and Its Dangers, op. cit., p. 53.

${ }^{29}$ K. Popper, Normal Science and Its Dangers, op. cit., p. 54.

30 P. Godfrey-Smith, Theory and Reality, op. cit., p. 98.

31 P. Feyerabend, Consolations for the Specialist, op. cit., p. 208. 
account offered more possibility for a psychological attitude, not necessarily "at the expense" of critical thinking, the impression Popper could have made.

Nickles suggests that Popper had "the grand, romantic picture of science as the field of play of artistic geniuses" 32 with which Kuhn's idea was fiercely compared (Nickles uses the word "overreaction" $\left.{ }^{33}\right)$. Feyerabend's insight might seem more balanced. He argued for the possibility of having institutions organize the scientific practice without restricting individual interests or talents. Yet to advance the development and articulation of ideas, an individual needs a community that is both open to novelty and defending the earlier ideas. ${ }^{34}$ Such a balance between the ideal and a critical yet practical version of science means reaching the positive aim that other philosophers leave unmentioned: happiness.

\section{Conclusion}

This paper has shown a variety of ways of understanding "good science", and this influences the possible assessment of normal science. It could be argued that the synthesis of Kuhn's and Popper's views is difficult as these views tend to contradict each other, each with its own advantages and disadvantages. Feyerabend's attitude seems most balanced, but I think that the whole discussion shows a general problem. By introducing a rather "subjective" criterion of science, Kuhn and philosophers sympathetic to his thought have opened the way of ambiguous interpretation of science. The discussion developed into speaking of qualities that are important, but difficult to measure. Feyerabend has tried to outline a more probable, clearer mechanism than Kuhn but has introduced anoth-

32 T. Nickles, Normal Science: From Logic to Case-Based and Model-Based Reasoning, [in:] Thomas Kuhn, ed. T. Nickles, Cambridge 2003, p. 143.

${ }^{33}$ T. Nickles, Normal Science: From Logic to Case-Based and Model-Based Reasoning, op. cit., p. 143.

34 P. Feyerabend, Consolations for the Specialist, op. cit., p. 209-210. 
er subjective criterion. That is why it could be argued that normal science will always remain a science with both "good" and "bad" aspects. Because of the margin of subjectivity its concept holds and somehow encourages, there will never be one clear-cut set of criteria to apply as its goal or final ideal outcome, and, hence, normal science can be constantly criticized and praised.

\section{Summary}

\section{Is normal science good science?}

"Normal science" is a concept introduced by Thomas Kuhn in The Structure of Scientific Revolutions (1962). In Kuhn's view, normal science means "puzzle solving", solving problems within the paradigm—-framework most successful in solving current major scientific problems-rather than producing major novelties. This paper examines Kuhnian and Popperian accounts of normal science and their criticisms to assess if normal science is good. The advantage of normal science according to Kuhn was "psychological": subjective satisfaction from successful "puzzle solving". Popper argues for an "intellectual" science, one that consistently refutes conjectures (hypotheses) and offers new ideas rather than focus on personal advantages. His account is criticized as too impersonal and idealistic. Feyerabend's perspective seems more balanced; he argues for a community that would introduce new ideas, defend old ones, and enable scientists to develop in line with their subjective preferences. The paper concludes that normal science has no one clear-cut set of criteria encompassing its meaning and enabling clear assessment.

Keywords normal science, Thomas Kuhn, Karl Popper, Paul Feyerabend, scientific revolution

\section{Bibliography}

Baker A., Simplicity, http://plato.stanford.edu/archives/sum2011/entries/simplicity/ (1.02.2013).

Feyerabend P., Consolations for the Specialist, [in:] Criticism and the Growth of Knowledge. Proceedings of the International Colloquium in the Philosophy of Science, ed. I. Lakatos, A. Musgrave, London 1965, Cambridge 1970.

Godfrey-Smith P., Theory and Reality: An Introduction to the Philosophy of Science, Chicago-London 2003. 
Hacking I., Introductory Essay, [in:] T. S. Kuhn, The Structure of Scientific Revolutions. Fourth Edition, Chicago-London 2012.

Kuhn T. S., Logic of Discovery or Psychology of Research?, [in:] Criticism and the Growth of Knowledge. Proceedings of the International Colloquium in the Philosophy of Science, ed. I. Lakatos, A. Musgrave, London 1965, Cambridge 1970.

Kuhn T.S., The Structure of Scientific Revolutions, The University of Chicago Press, Chicago - London 2012.

Nickles T., Normal Science: From Logic to Case-Based and Model-Based Reasoning, [in:] Thomas Kuhn, ed. T. Nickles, Cambridge 2003.

Popper K., Normal Science and Its Dangers, [in:] Criticism and the Growth of Knowledge. Proceedings of the International Colloquium in the Philosophy of Science, ed. I. Lakatos, A. Musgrave, London 1965, Cambridge 1970.

Popper K., Conjectures and Refutations. The Growth of Scientific Knowledge, London-New York 2004.

Watkins J., Against 'Normal Science', [in:] Criticism and the Growth of Knowledge. Proceedings of the International Colloquium in the Philosophy of Science, ed. I. Lakatos, A. Musgrave, London 1965, Cambridge 1970. 